\title{
THE PERFORMANCE EVALUATION OF A PLATE TYPE EVAPORATOR AND A SHELL AND TUBE EVAPORATOR
}

\author{
Lucky Ugochukwu Adoh ${ }^{1}$, Ola Victor, Damilare ${ }^{2}$ \\ E-Mail Id: Luckyadoh4real@gmail.com, olavictord@gmail.com² \\ ${ }^{1}$ Department of Mechanical Engineering, Federal University of Technology, Akure, PMB 704, Ondo \\ State, Nigeria \\ ${ }^{2}$ Federal University of Technology, Akure, PMB 704, Ondo State, Nigeria
}

\begin{abstract}
In this paper, a refrigeration system using shell and tube evaporator will be converted to a refrigeration system using a plate type evaporator. The performance of the modified system will be evaluated and compared with the performance of the plate type evaporator. A refrigeration system working on a shell and tube evaporator was selected, charged with refrigerant R134a. Temperature and pressure readings were taken at both the inlet and outlet of both the evaporator and condenser unit respectively. The refrigeration system with shell and tube evaporator was then removed and replaced with a plate type evaporator. The system was evacuated, charged with refrigerant and readings were taken at both the inlet and outlet of the evaporator and condenser respectively. Experimental results obtained shows that the refrigeration efficiency of the shell and tube evaporator was $64.33 \%$ and that of the plate type evaporator was $85.24 \%$. The result obtained shows that the COP of the refrigerator using the plate type evaporator is higher than that of the refrigerator using the shell and tube evaporator. The refrigeration system working on a plate type evaporator has higher refrigeration capacity and lower compressor work, low liquid hold up, higher surface area than the shell and tube evaporator system.
\end{abstract}

Keywords: Coefficient of Performance, Evaporator, Plate type, refrigerant, Refrigeration system, Shell and tube.

\section{INTRODUCTION}

Refrigeration is defined as the process of extracting heat from a lower-temperature heat source, substance, or cooling medium and transferring it to a higher-temperature heat sink. Refrigeration maintains the temperature of the heat source below that of its surroundings while transferring the extracted heat, and any required energy input, to a heat sink, atmospheric air, or surface water [1]. Refrigeration is therefore the opposite of the natural flow of heat. In simple, refrigeration means the cooling of or removal of heat from a system. The equipment employed to maintain the system at a low temperature is termed as refrigerating system and the system which is kept at lower temperature is called refrigerated system. Refrigeration is generally produced in one of the following three ways: (i) By melting of a solid. (ii) By sublimation of a solid. (iii) By evaporation of a liquid. Most of the commercial refrigeration is produced by the evaporation of a liquid called refrigerant [2]. It has many applications in everyday life including chilling, freezing, and air-conditioning. This is achieved by continuous extraction of heat from the enclosed space so that the temperature is maintained below that of the surrounding temperature. The medium with which this heat is removed is known as a refrigerant otherwise referred to as working fluid. This working fluid picks up heat from the space to be cooled, by evaporating at low temperature and low pressure, and dissipate it by condensing at high temperature and high pressure. Refrigeration has many applications which may include: preservation of household perishable food items and drinks, industrial cooling, cryogenics and air conditioning amongst others. There are three (3) main classifications of refrigeration system according to their working principle, these include: vapour compression; vapour absorption-, and gas cycle refrigeration systems. However, vapour compression refrigeration system (VCRS) is the most frequently used amongst others classified and the major components of VCRS include: compressor, condenser, expansion valve universally known as throttling device and evaporator [3].

However, vapour compression refrigeration system (VCRS) is the most popular and commonly used domestic refrigeration system. Refrigerating system consist of the following parts:

$>$ Evaporator: It consists of coils of pipe in which the liquid-vapour refrigerant at low temperature and pressure is evaporated and changed into vapour at low pressure and temperature.

$>$ Compressor: low temperature and pressure vapour refrigerant is drawn into the suction or inlet valve and then compressed to high temperature and pressure. The high temperature and pressure vapour refrigerant is then discharged into the condenser with a discharge or delivery tube.

$>$ Condenser: it consists of coils of pipe in which the high temperature and vapour refrigerant is condensed and cooled.

$>$ Expansion valve: it is also called the throttling or refrigerant control valve. Its function is to allow the liquid refrigerant under high temperature and pressure to pass at a controlled rate after reducing its pressure and temperature. 


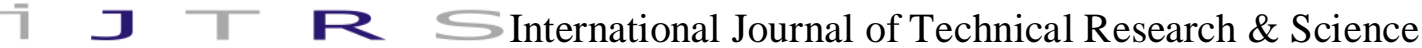

Most refrigerants undergo a series of evaporation, compression, condensation, throttling, and expansion processes, absorbing heat from a lower-temperature reservoir and releasing it to a higher temperature reservoir in such a way that the final state is equal in all respects to the initial state. It is said to have undergone a closed refrigeration cycle. When air or gas undergoes a series of compression, heat release, throttling, expansion, and heat absorption processes, and its final state is not equal to its initial state, it is said to have undergone open refrigeration cycle [1].

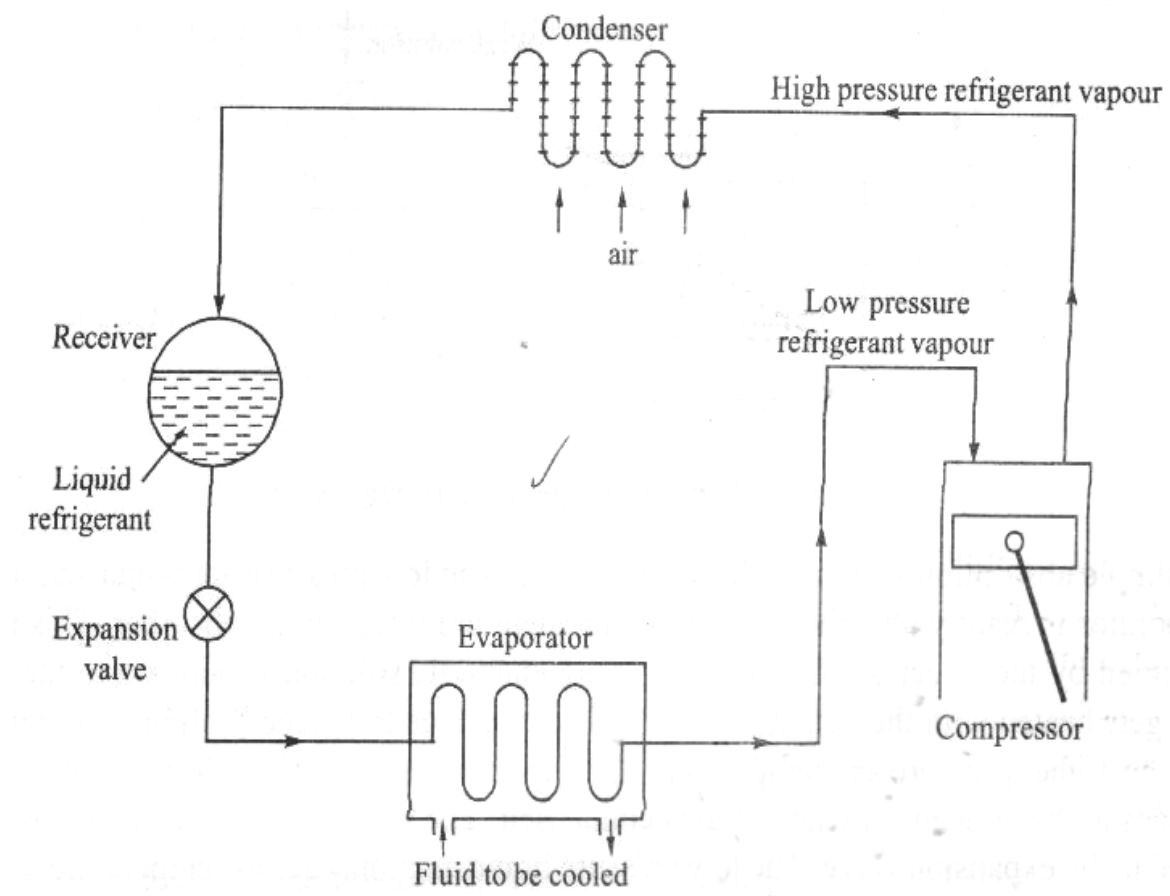

Fig. 1.1 Refrigeration Cycle

The problem to be solved in this paper is to improve the refrigerating capacity of a refrigerating system by replacing a shell and tube type evaporator with a plate type evaporator. The coefficient of performance of the refrigerating system with a shell and tube evaporator will be determined and compared with the refrigerating system of a plate type evaporator.

The aim of this project is to convert a refrigeration system using a shell and tube evaporator to refrigerating system using a plate type evaporator.

The specific objectives of this project are to:

$>$ Convert a selected refrigerating system using a plate type evaporator

$>$ Evaluate the performance of the modified system

$>$ Compare the performance of the shell and tube type evaporator with the plate type evaporator

\section{EVAPORATORS}

An evaporator is a device in a process used to turn the liquid form of a chemical substance such as water into its gaseous form [4]. The purpose of the evaporator is to remove unwanted heat from the product through the liquid refrigerant. The liquid refrigerant contained within the evaporator is boiling at a low-pressure. There are different classifications of evaporators but for the purpose of this research, we shall be considering the shell and tube type and the plate type evaporator.

\subsection{Shell and Tube Evaporator}

The shell-and-tube type evaporators are very efficient and require minimum floor space and headspace. These are easy to maintain; hence they are very widely used in medium to large capacity refrigeration systems. The shell-and-tube evaporators can be either dry type or flooded type. As the name implies, a shell-and-tube evaporator consists of a shell and a large number of straight tubes arranged parallel to each other. In dry expansion type, the refrigerant flows through the tubes while in flooded type the refrigerant is in the shell. A pump circulates the chilled water or brine [5].

\subsection{Plate Type Evaporators}

A plate type evaporator is a type of evaporator that uses metal plates to transfer heat between two fluids [6]. This has advantage over the other types of evaporators in that the fluids are exposed to a much larger surface area because the fluids are spread out over the plates. This facilitates the transfer of heat and greatly increases the speed of the temperature exchange. Plate type evaporators are used when a close temperature approach $(0.5$ 
] $\longrightarrow$ S International Journal of Technical Research \& Science

$\mathrm{K}$ or less) between the boiling refrigerant and the fluid being chilled is required. The overall heat transfer coefficient of these plate type evaporators is very high. In addition, they also require very less refrigerant inventory for the same capacity (about 10 percent or even less than that of shell-and-tube type evaporators). Another important advantage is that, it is very easy to clean the evaporator and assemble it back as and when required. The capacity can be increased or decreased very easily by adding or removing plates. Hence, these evaporators are finding widespread use in a variety of applications.

\subsubsection{Advantage of Plate Type Evaporator over Shell and Tube Evaporator}

The conversion of refrigerating system using a shell and tube evaporator to a refrigerating system using a plate type evaporator will definitely increase the refrigerating capacity of the refrigerator and also, improve the coefficient of performance of the refrigerating system due to the advantages of plate type evaporator over shell and tube evaporator which are as follows;

$>$ High heat transfer efficiency

$>$ Easily cleaned

$>$ Maintenance is simple

$>$ Leaking plates can be removed in pairs, if necessary, without replacement

$>$ Capacity can be increased by introducing plate in pairs

$>$ Improve the quality of the product

$>$ Save users input costs and space [7].

\section{MATERIAL AND METHODS}

Materials and equipment used for this research work are; Flat plate evaporator, Shell and tub evaporators, Oxyacetylene kit, silvus rod, brass rod, and dryer, refrigerant. R134a, stop watch, thermometer (mercury-in-glass).

\subsection{Evacuation of Refrigeration System}

Evacuation is a process removing moisture and dirt from the refrigeration system using a vacuum. The manifold gauge is used for this purpose. It consists of the suction and discharge pressure gauge. It simplifies the servicing and charging of the refrigerating system.

The following procedures were taken for the evacuation of the refrigerator,

$>$ The low-pressure side(blue) of the gauge was connected to the suction service valve of the compressor, the high-pressure side of the gauge was closed through the high side shut of the valve

$>$ The middle line (yellow) was connected to the vacuum pump

$>$ The vacuum pump was switched on and was allowed to run, a vacuum reading of $760 \mathrm{mmhg}$ was obtained.

$>$ The high vacuum removes all the fluids and the system is now ready for charging with refrigerant.

\subsection{Charging with Refrigerant R1343}

This refers to the process by which refrigerant is added to the system. After evacuation, the following steps were taken for charging of refrigerant into the system:

$>$ The low-pressure side (blue) of the gauge was connected to the suction services valve of the compressor; the high-pressure side of the gauge was closed through the high side shut off valve.

$>$ The middle line (yellow) was connected to the refrigerant cylinder,

$>$ Refrigerator was switched on.

$>$ The cylinder was opened to allow refrigerant into system.

$>$ The cylinder was locked after the correct amount of refrigerant has entered the system.

\subsection{Leak Testing}

After assembling the components, all joints were tested for leaks using soap bubble method. Leak spots were detected and sealed properly.

\subsection{Testing of the Refrigerating System}

After assembling the components, the refrigerator was connected to a power source and switched on. It was allowed to run for twenty minutes for testing purposes. It was observed by feeling with the hand that there was increase in temperature of the condenser and decrease in temperature of the evaporator which is an indication that the system is working.

\subsection{Experimental Setup and Procedures}

Towards realizing the research objectives, the steps itemized below will serve as the navigator directing point of action to take place at a specific time.

$>$ Review of relevant literature

$>$ Experimental set up and testing

$>$ Getting the data and analyzing the experimental results. 


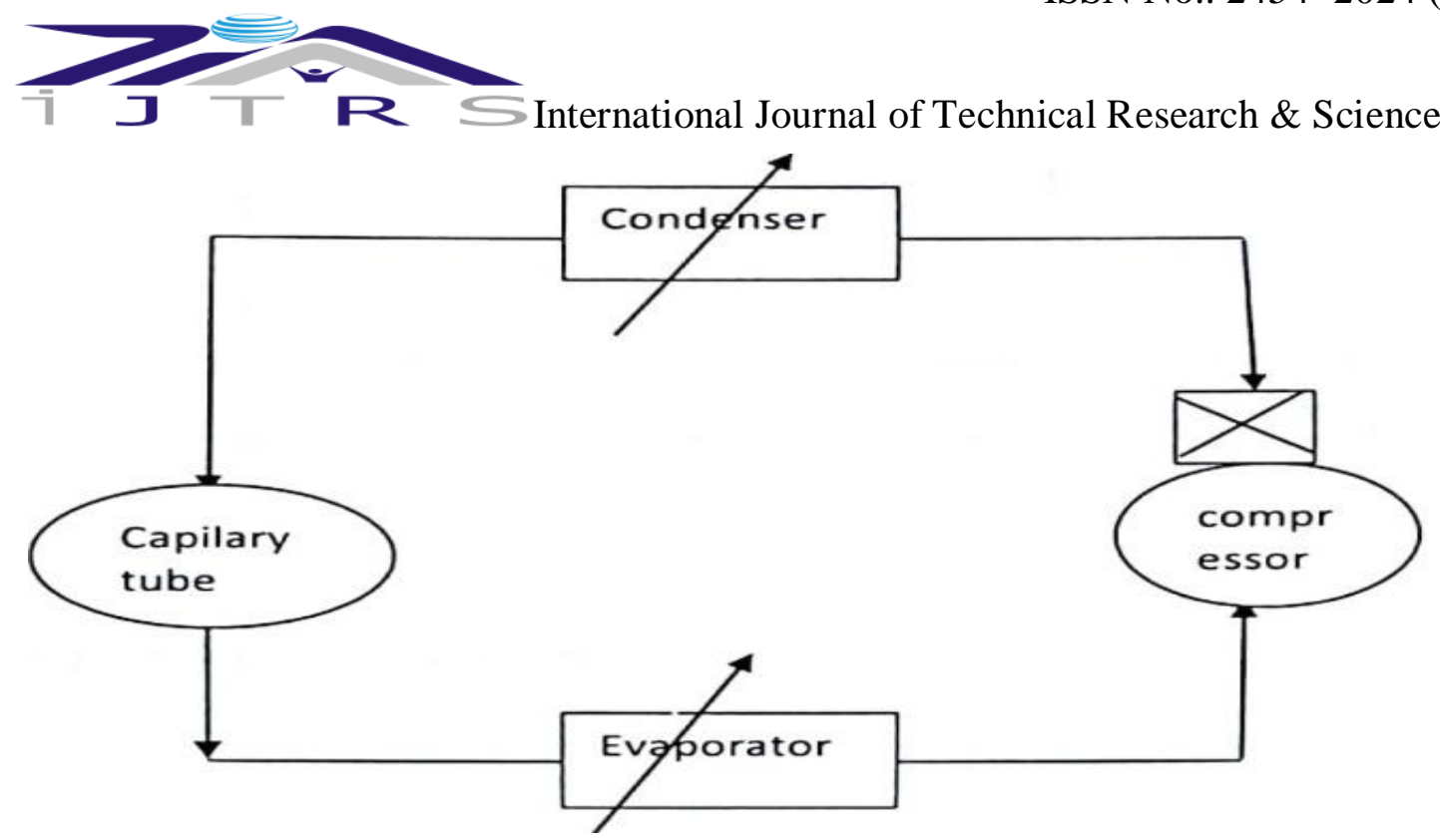

Fig. 3.1Experimental Setup

\subsection{Experimental Procedures}

- From the selected refrigerator using shell and tube refrigerator

$>$ Evacuate the system

$>$ Charge with refrigerant R134a

$>$ Run and test for leakage

$>$ Take readings from the thermometer, for the condenser and evaporator outlet and inlet temperature readings

$>$ Repeat (d) for five different times at 5 minutes intervals

$>$ Compute data and analyze results

- Remove the shell and tube evaporator and replace it with the plate type evaporator

- From the refrigeration system using a plate type evaporator

$>$ Evacuate the system

$>$ Charge with refrigerant R134a

$>$ Run and test for leakage

$>$ Take readings from the thermometer, for the condenser and evaporator outlet and inlet temperature readings

$>$ Repeat (d) for five different times at 5 minutes intervals

$>$ Compute data and analyze results

\subsection{Refrigerating Effect}

Refrigerating effect is defined as the amount of heat that is absorbed by the refrigerant as it passes through the evaporator.

Refrigerating effect $=(\mathrm{h} 1-\mathrm{h} 4)(\mathrm{KJ} / \mathrm{KG})$

\subsection{Compressor}

In a refrigeration cycle, the compressor has two main functions within the refrigeration cycle. One of the functions is to draw in refrigerant vapor from the evaporator so that the desired temperature and pressure can be achieved. The second function is to increase the pressure as well as the temperature of the refrigerant vapor through the process of compression. The compressor used for this project is a hermatic seal vapor compressor which serves as the engine of the refrigerator, with a size of $0.2 \mathrm{HP}$.

Compressor capacity, $\mathrm{Q}_{\text {comp }}$

$\mathrm{Q}_{\text {comp }}=\mathrm{m}_{\mathrm{c}}(\mathrm{h} 2-\mathrm{h} 1)$

where,

$$
\begin{aligned}
& \mathrm{h} 2=\text { Enthalpy }(\mathrm{KJ} / \mathrm{Kg}) \text { at compressor outlet } \\
& \mathrm{h} 1=\text { Enthalpy }(\mathrm{KJ} / \mathrm{Kg}) \text { at compressor inlet } \\
& \mathrm{Mc}=\text { mass flow rate of the compressor }
\end{aligned}
$$

\subsection{Condenser}

The heat absorbed by the refrigerant in the evaporator is rejected to the atmosphere through the condenser. The condenser used for this project is an air-cooled condenser.

The heat absorbed by the condenser is given by,

Qcond $=\mathrm{m}(\mathrm{h} 2-\mathrm{h} 3)$

where, 


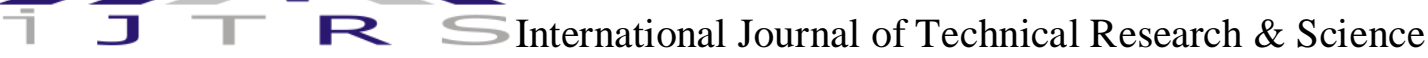
$\mathrm{m}=$ mass flow rate through the condenser $(\mathrm{kg} / \mathrm{s})$

\subsection{Capillary Tube}

The capillary tube is a copper tube of very small internal diameter tube through which the refrigerant flows into the evaporator. It reduces the condensing pressure to the evaporating pressure in the copper tube.

\subsection{Dryer}

A dryer is a device to trap the moisture, small metal chips, and dirt in the refrigerant from entering the system which can restrict the free flow of refrigerant into the capillary tube.

\subsection{Determination of Coefficient of Performance (COP)}

According to the first law of thermodynamics, the measure of performance of the refrigeration cycle is the coefficient of performance (COP) and is the refrigeration effect produced per unit of work required or the compressor power consumption. It is expressed as:

$$
\text { Cop }=\frac{\text { refrigerating effet }}{\text { work done by compressor }}=\frac{h 1-h 3}{h 2-h 1}
$$

\section{RESULT AND DISCUSSION}

On conclusion of the experiment, the values of T1, T2, T3, H1, H2, H3, were recorded. The refrigerating effect, work done by compressor, coefficient of performance and refrigeration efficiency are calculated and recorded. The readings for the shell and tube evaporator are recorded below;

From the property table for saturated refrigerant R134a, the enthalpy values are gotten for the corresponding temperature.

$\mathrm{T} 1=$ temperature at compressor inlet

$\mathrm{T} 2=$ temperature at compressor outlet

$\mathrm{T} 3$ = temperature inside the evaporator

$\mathrm{H} 1$ = enthalpy corresponding to temperature, $\mathrm{Tl}$

$\mathrm{H} 2$ = enthalpy corresponding to temperature, $\mathrm{T} 2$

$\mathrm{H} 3$ = enthalpy corresponding to temperature, $\mathrm{T} 3$

Table-4.1 Temperature Reading for Shell and Tube Evaporator

\begin{tabular}{|l|l|l|l|l|}
\hline S. No. & Time $(\mathbf{m i n s})$ & $\left.\mathbf{T 1}\left({ }^{\mathbf{0}} \mathbf{C}\right)\right)$ & $\mathbf{T 2}\left({ }^{\mathbf{0}} \mathbf{C}\right)$ & $\mathbf{T 3}\left({ }^{\mathbf{0}} \mathbf{C}\right)$ \\
\hline 0 & 0 & 31 & 40 & 6 \\
\hline 1 & 30 & 30 & 42 & 4 \\
\hline 2 & 60 & 29 & 43 & 2 \\
\hline 3 & 90 & 28 & 46 & -2 \\
\hline 4 & 120 & 27.5 & 48 & -6 \\
\hline 5 & 150 & 27 & 50 & -8 \\
\hline 6 & 180 & 26 & 52 & -10 \\
\hline
\end{tabular}

From the property table for saturated refrigerant R134a, the enthalpy values are gotten for the corresponding temperature.

Table-4.2 Enthalpy Reading for Shell and Tube Evaporator

\begin{tabular}{|l|l|l|l|}
\hline Time(mins) & $\mathbf{H}_{\mathbf{1}}(\mathbf{K J} / \mathbf{K G})$ & $\mathbf{H}_{\mathbf{2}}(\mathbf{K J} / \mathbf{K G})$ & $\mathbf{H}_{\mathbf{4}}(\mathbf{K J} / \mathbf{K G})$ \\
\hline 0 & 267.14 & 271.27 & 59.97 \\
\hline 30 & 266.66 & 272.72 & 57.25 \\
\hline 60 & 267.17 & 272.54 & 54.55 \\
\hline 90 & 265.68 & 273.75 & 49.17 \\
\hline 120 & 265.43 & 274.53 & 43.84 \\
\hline 150 & 265.18 & 275.26 & 41.19 \\
\hline 180 & 264.68 & 275.98 & 38.55 \\
\hline
\end{tabular}

The refrigerating effect, work done by compressor and coefficient of performance is calculated and tabulated.

DOI Number: https://doi.org/10.30780/IJTRS.V04.I09.001

pg. 5

www.ijtrs.com

www.ijtrs.org 
I R SInternational Journal of Technical Research \& Science

Table-4.3 Refrigerating Effect, Work Done by Compressor and Cop for Shell and Tube Evaporator

\begin{tabular}{|l|l|l|l|}
\hline Time(mins) & Refrigeration effect(kj/kg) & Compressor work & COP \\
\hline 0 & 59.97 & 4.13 & 14.52 \\
\hline 30 & 57.25 & 5.46 & 10.49 \\
\hline 60 & 54.55 & 6.37 & 8.56 \\
\hline 90 & 49.17 & 8.07 & 6.09 \\
\hline 120 & 43.84 & 9.1 & 4.82 \\
\hline 150 & 41.19 & 10.08 & 4.09 \\
\hline 180 & 38.55 & 11.3 & 3.41 \\
\hline & Average $=49.22$ & Average $=7.78$ & Average $=7.43$ \\
\hline
\end{tabular}

\subsection{Refrigeration Efficiency for Shell and Tube Evaporator}

Temperature limit for condenser, $\mathrm{T} 2=45^{\circ} \mathrm{C}(318 \mathrm{k})$

Refrigerating effect $=49.22 \mathrm{kj} / \mathrm{kg}$

Work done by compressor $=7.78 \mathrm{kj} / \mathrm{kg}$

Theoretical COP $=7.43$

Temperature limit for evaporator, $\mathrm{T} 1=10^{\circ} \mathrm{C}(263 \mathrm{k})$

$$
\begin{aligned}
& \text { COP actual }=\frac{T 1}{T 2-T 1} \\
& \text { COPactual }=\frac{263}{318-263}
\end{aligned}
$$

$\mathrm{COP}$ actual $=4.78$

$$
\text { Refrigeration efficiency }=\frac{\text { COP actual }}{\text { COP theoretical }}
$$

Refrigeration efficiency $=\eta=64.33 \%$

\subsection{Refrigeration efficiency for plate type evaporator}

Table-4.4 Temperature Reading for Plate Type Evaporator

\begin{tabular}{|l|l|l|l|l|}
\hline S. No. & Time(mins) & $\mathbf{T 1}^{\mathbf{0}} \mathbf{C}$ & $\mathbf{T 2}^{\mathbf{0}} \mathbf{C}$ & $\mathbf{T 3}^{\mathbf{0}} \mathbf{C}$ \\
\hline 0 & 0 & 28 & 48 & 14 \\
\hline 1 & 30 & 30 & 49 & 12 \\
\hline 2 & 60 & 32 & 52 & 8 \\
\hline 3 & 90 & 34 & 55 & 6 \\
\hline 4 & 120 & 35 & 59 & 2 \\
\hline 5 & 150 & 36 & 60 & 0 \\
\hline 6 & 180 & 37 & 65 & -2 \\
\hline
\end{tabular}

From the property table of refrigerant $\mathrm{R} 134 \mathrm{a}$, enthalpy values are gotten for the corresponding temperature values.

Table-4.5 Enthalpy Reading for Plate Type Evaporator

\begin{tabular}{|l|l|l|l|}
\hline Time(mins) & $\mathbf{H}_{\mathbf{1}}(\mathbf{K J} / \mathbf{K G})$ & $\mathbf{H}_{\mathbf{2}}(\mathbf{K J} / \mathbf{K G})$ & $\mathbf{H}_{\mathbf{4}}(\mathbf{K J} / \mathbf{K G})$ \\
\hline 0 & 265.68 & 274.53 & 70.95 \\
\hline 30 & 266.17 & 274.89 & 62.69 \\
\hline 60 & 267.14 & 275.62 & 59.97 \\
\hline 90 & 267.62 & 275.98 & 57.25 \\
\hline 120 & 268.87 & 276.97 & 54.55 \\
\hline 150 & 269.03 & 277.30 & 51.86 \\
\hline 180 & 269.40 & 278.17 & 49.17 \\
\hline
\end{tabular}

DOI Number: https://doi.org/10.30780/IJTRS.V04.I09.001

pg. 6

www.ijtrs.com

www.ijtrs.org

Paper Id: IJTRS-V4-I5-028

Volume IV Issue IX, September 2019

@2017, IJTRS All Right Reserved 
ISSN No.: 2454- 2024 (online)

ᄀ 1 R $S$ International Journal of Technical Research \& Science

Table-4.6 The Refrigerating Effect, Compressor Work and Coefficient of Performance for Plate Type Evaporator

\begin{tabular}{|c|c|c|c|}
\hline Time (mins) & $\begin{array}{l}\text { Refrigeration Effect } \\
\text { (KJ/KG) }\end{array}$ & $\begin{array}{l}\text { Compressor } \\
\text { (KG/KG) }\end{array}$ & COP \\
\hline 0 & 70.93 & 5.57 & 12.73 \\
\hline 30 & 62.69 & 6.67 & 9.39 \\
\hline 60 & 59.97 & 7.69 & 7.80 \\
\hline 90 & 57.25 & 7.57 & 7.56 \\
\hline 120 & 54.55 & 8.69 & 6.28 \\
\hline 150 & 51.86 & 8.74 & 5.93 \\
\hline \multirow[t]{2}{*}{180} & 47.17 & 8.87 & 5.32 \\
\hline & Average $=57.78$ & Average $=7.69$ & Average $=7.86$ \\
\hline
\end{tabular}

Refrigerating effect $=57.78 \mathrm{KJ} / \mathrm{KG}$

Work done by compressor $=7.6 \mathrm{KJ} / \mathrm{KG}$

Theoretical $\mathrm{COP}=7.86$

Temperature limit for condenser, $\mathrm{T} 2=35^{\circ} \mathrm{C}(380 \mathrm{k})$

Temperature limit for evaporator, $\mathrm{T} 1=-5^{\circ} \mathrm{C}(268 \mathrm{k})$

$$
\begin{gathered}
\text { COP actual }=\frac{268}{300-268}=6.7 \\
\text { Refrigeration efficiency }=\frac{6.7}{7.86}=85.24 \%
\end{gathered}
$$

Table-4.7 Comparison between Plate Type and Shell and Tube Evaporator

\begin{tabular}{|l|l|l|}
\hline & Shell and tube Evaporator & Plate type Evaporator \\
\hline Refrigeration effect (KJ/KG) & 49.22 & 57.78 \\
\hline Compressor work (KJ/KG) & 7.78 & 7.6 \\
\hline COP theoretical & 7.43 & 7.86 \\
\hline COP actual & 4.78 & 6.7 \\
\hline Refrigeration efficiency & 64.33 & 85.24 \\
\hline
\end{tabular}

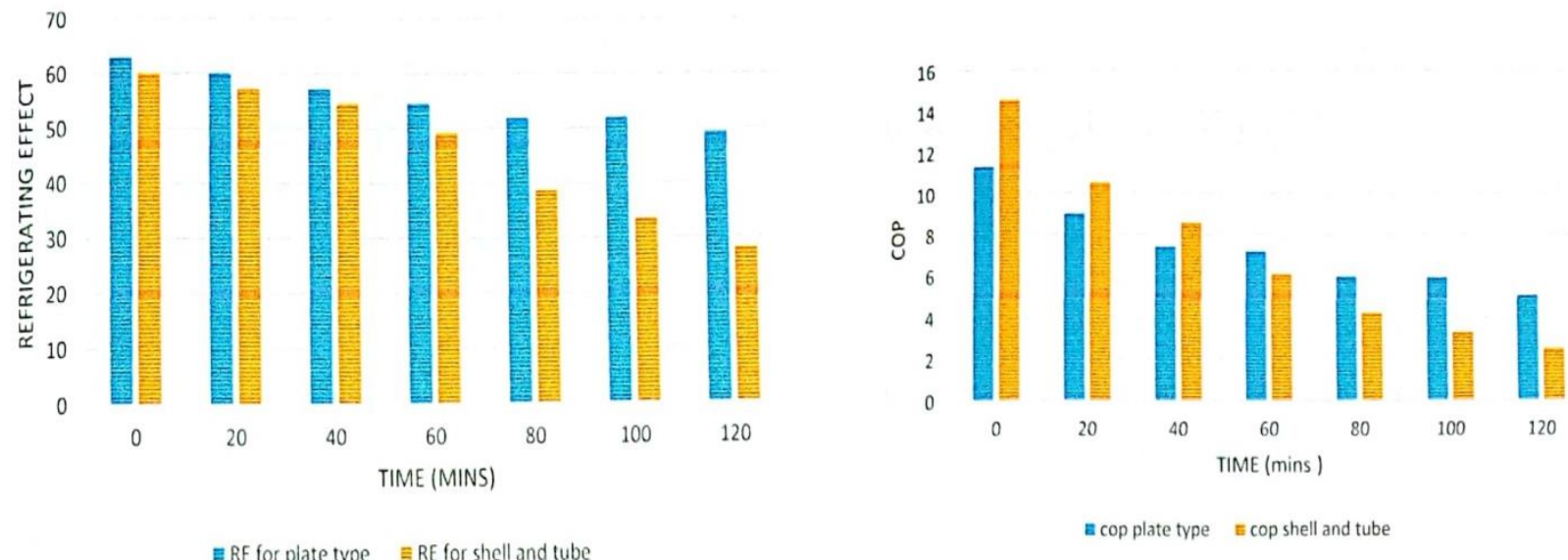

Fig. 4. Refrigeration Effect Against Time

Fig. 4.2 Cop Against Time

\section{CONCLUSIONS}

A refrigeration system working on both the Shell and tube and Plate type Evaporator has been successfully investigated. The coefficient of performance of the refrigerator with shell and tube evaporator was determined and compared with the refrigeration system with a plate type evaporator. The result obtained shows that the $\mathrm{COP}$ of the refrigeration system using the plate type evaporator is higher than that of the refrigerator using the shell and tube. The refrigerating capacity of the plate type evaporator is higher than that of the shell and tube evaporator. On conclusion of the experiment the following findings are observed:

$>$ The plate type evaporator has higher refrigeration efficiency than the shell and tube.

DOI Number: https://doi.org/10.30780/IJTRS.V04.I09.001

pg. 7

www.ijtrs.com

www.ijtrs.org

Paper Id: IJTRS-V4-I5-028

Volume IV Issue IX, September 2019

@2017, IJTRS All Right Reserved 
7 $\mathrm{F} \leqq$ International Journal of Technical Research \& Science

$>$ The plate type evaporator has a higher refrigerating effect than the shell and tube.

$>$ The plate type evaporator has a higher coefficient of performance than the shell and tube

$>$ The plate type evaporator has low liquid hold up and better cooling capacity than the shell and tube evaporator.

$>$ The plate type evaporator requires lesser energy to operate, hence, reduce cost of running refrigeration equipment and enhance the performance of a refrigeration system.

\section{REFERENCES}

[1] Shan K Wang. (2000) ''Refrigerant, refrigeration cycle and refrigeration system' in HandbookCof air conditioning and refrigeration, 2nd edition, Newyork, McGraw-Hill, ch. 9, pp. 404.

[2] R.K. Rajput (2012) 'Refrigeration cycle' Engineering Thermodynamics, New-Delhi, India, Laxmi publications Ltd, Ch. 14, pp. 713.

[3] Farayibi P.K, Mogaji T.S., and Erinle T.J. (2015), "Effect of throttling variation on the performance of vapour compression refrigeration system," British Journal of Applied Science and Technology, ISSN: 2231-0843, Article no. BJAST.23086, pp. 2.

[4] Wikipedia(2018,April30).'Plateheatexchanger'’[Online],Available:Http://www.wikipedia.org/wiki/evapor ators.

[5] Indian Insitute of Technology Kharagpur (2016). Refrigeation and Air Conditioning [online]. Available: http/:www.iitkgp.ac.in [Accessed : 10 July 2018]

[6] Wikipedia(2018,April22).'Plateheatexchanger'’[Online],Available:Http://www.wikipedia.org/wiki/plate_h eat_exchanger.

[7] Marine engineering Study Materials (2014). " Advantage and disadvantages of Plate Type and Shell and Tube heat exchangers", [Online]. Available: https://marineengineeringonline.com/advantagesdisadvantages-shell-tube-plate-type-heat-exchangers/

[8] Adrian B. (1948) Advanced engineering Thermodynamics, Wiley-interscience publications, Canada.

[9] Anderson, 0. E (1953). Refrigeration in America; a history of a new Technology and its impact. (Princaton), Published for the University of Vincinnati by Princeton University press. pp.5-6. ISBN 0804616213.

[10] Anderson, 0. E, (1972) Refrigeration in America: A history of a new technology and its impact Kennikat press.

[11] Rajput, RK. (2012) A textbook of Engineering Thermodynamics,Laxmi publications(p)Ltd, newdelhi, india.

[12] Freidberg, S. (2010). Fresh: a perishable history (1St Harvard University Press pbk. ed .ed) Cambridge, Mass: Belknap.pp.20 23. ISBN 0674057228.

[13] Norborg, D. (2007) .Introduction to the basics of refrigeration, AISCAC-DSUHBS.

[14] Khurrni, RS and Gupta, J.K. (1987) A textbook of Refrigeration and Air conditioning, S. Chand publishing, New deihi, India.

[15] Cabello, R., Torrella, E., Navarro Esbri, J. (2004), Experimental evaluation of a vapour compression plant performance using R134a, RR407C and R22 as working fluids, Applied Thermal Engineering 241905 1917.

[16] Stoecker W.F., Jones .l.W (1982), Refrigeration and AirConditioning, 2"‘1 Edition, London: McGrawHill, 